\title{
A EDUCAÇÃO INTERCULTURAL COMO POSSIBILIDADE EM PROCESSOS DECOLONIAIS NA GARANTIA DOS DIREITOS DA INFÂNCIA
}

\author{
LA EDUCACIÓN INTERCULTURAL COMO POSIBILIDAD EN PROCEDIMIENTOS \\ DECOLONIALES EN LA GARANTÍA DE LOS DERECHOS DE LA INFANCIA
}

\section{INTERCULTURAL EDUCATION AS A POSSIBILITY IN DECOLONIAL PROCEDURES IN THE GUARANTEE OF CHILDHOOD RIGHTS}

\author{
Eduardo Felipe Hennerich PACHECO ${ }^{1}$ \\ Ana Maria $\mathrm{EYNG}^{2}$
}

RESUMO: Efeitos advindos dos processos coloniais perduram na violação de direitos e atuam na configuração da pobreza infantil no contexto da América Latina. Na discussão destacamos o par pobreza infantil e colonialismo, que ainda andam de mãos fortemente unidas, atuando na violação de direitos de provisão, proteção e participação da infância. Esse cenário que se reproduz com grande frequência em diversos países latino americanos está representado nas falas de meninas e adolescentes da Guatemala, ouvidas mediante entrevistas individuais. A garantia dos direitos da infância requer a superação dos efeitos dos processos coloniais, enraizados culturalmente. Nessa direção, a constituição de processos decoloniais via educação intercultural possibilita que a pobreza infantil na perspectiva multidimensional seja gradativamente superada.

PALAVRAS-CHAVE: Pobreza infantil. Direitos humanos. Decolonialidade. Educação intercultural.

RESUMEN: Efectos provenientes de los procesos coloniales perduran en la violación de derechos y actúan en la configuración de la pobreza infantil en el contexto de América Latina. En la discusión destacamos el par pobreza infantil y colonialismo, que aún andan de manos fuertemente unidas, actuando en la violación de derechos de provisión, protección y participación de la infancia. Este escenario que se reproduce con gran frecuencia en diversos países latinoamericanos está representado en las conversaciones de niñas y adolescentes de Guatemala, escuchadas mediante entrevistas individuales. La garantía de los derechos de la infancia requiere la superación de los efectos de los procesos coloniales, arraigados culturalmente. En esa dirección, la constitución de procesos de colonización vía educación intercultural posibilita que la pobreza infantil en la perspectiva multidimensional sea gradualmente superada.

\footnotetext{
${ }^{1}$ Pontifícia Universidade Católica do Paraná (PUCPR), Curitiba - PR - Brasil. Doutorando em Educação pelo Programa de Pós-graduação em Educação da PUCPR. Bolsista da Coordenação de Aperfeiçoamento de Pessoal de Nível Superior (CAPES). OrcID: http://orcid.org/0000-0003-1498-2351. E-mail: eduardo.pva@ hotmail.com ${ }^{2}$ Bolsista Produtividade CNPq; Pontifícia Universidade Católica do Paraná (PUCPR), Curitiba - PR - Brasil. Docente e pesquisadora do Programa de Pós-graduação em Educação da PUCPR. Professora colaboradora no Instituto de Educação (IE) da Universidade do Minho. OrcID: http://orcid.org/0000-0003-0224-5880. E-mail: eyng.anamaria@gmail.com
} 
PALABRAS CLAVE: Pobreza infantil. Derechos humanos. Descolonialidad. Educación intercultural.

ABSTRACT: Effects from colonial processes persist in the violation of rights and act in the configuration of child poverty in the Latin America context. In the discussion we highlight the pair of child poverty and colonialism, which still walk hand in hand, acting in violation of rights of provision, protection and participation of children. This scenario, which is very frequently reproduced in several Latin American countries, is represented in the statements of Guatemalan girls and adolescents, heard through individual interviews. Ensuring the rights of children requires overcoming the effects of culturally rooted colonial processes. In this direction, the constitution of decolonial processes through intercultural education allows child poverty in the multidimensional perspective to be gradually overcome.

KEYWORDS: Child poverty. Human rights. Decoloniality. Intercultural education.

\section{Introdução}

A infância como categoria de marcação identitária é relativamente nova, advinda de uma trajetória histórica construída em processos coloniais, caracterizados pela invisibilidade e exclusão da criança, incidindo na garantia e proteção de seus direitos.

A história social da infância tem sua trajetória eivada por constante instabilidade e tutela de mecanismos de regulação social, mecanismos esses que foram denunciados e discutidos largamente nas obras de Michel Foucault (1994, 1985, 2010), como estruturas hierárquicas de opressão. $\mathrm{O}$ autor nomeou as esferas e instituições da sociedade que enquadram os sujeitos, seus corpos e suas vidas, incluindo família, religião, escola, clínica e prisão. As instituições, definidas pelo filósofo francês como instituições de governamento (FOUCAULT, 1994), assumiram na concretude de suas paredes a vigilância, normatização e punição dos indivíduos, cujas condutas se tornam tuteladas na esfera estatal. O conceito de governamento evidencia o papel que a política moderna assume em termos de relações de poder e define "a atividade que consiste em reger a conduta dos homens em um contexto e por meio de instrumentos estatais" (FOUCAULT, 1994, p. 819).

A infância, de maneira especial, esteve sempre tutelada pelas instituições de governamento, somente a partir do ano de 1989, a criança recebeu o status de sujeito de direitos, por meio da Convenção dos Direitos da Criança (CDC, 1989) adotada na Assembleia Geral das Nações Unidas (ONU). Os direitos de proteção, provisão e participação constituem os eixos centrais previstos na CDC, e assinalam um marco histórico na constituição dos direitos da infância. 
Os direitos de provisão compreendem o suprimento das necessidades via garantia dos direitos sociais, "[...] relativamente à salvaguarda da saúde, educação, segurança social, cuidados físicos, vida familiar, recreio e cultura”. Os direitos de proteção, por sua vez, compreendem "[...] os direitos da criança a ser protegida contra a discriminação, abuso físico e sexual, exploração, injustiça e conflito". E, o maior destaque, em termos de avanço e reconhecimento das crianças como sujeitos de direitos, está no conjunto de direitos relativos à participação, previstos na CDC. Os direitos de participação integram "[...] direitos civis e políticos, ou seja, aqueles que abarcam o direito da criança ao nome e identidade, o direito à liberdade de expressão e opinião e o direito a tomar decisões em seu proveito" (SOARES, 1997, p. 82).

Os países signatários da CDC assumem o compromisso de assegurar a garantia dos direitos previstos na convenção a toda e qualquer criança e adolescente, independentemente de características identitárias. Entretanto, os cenários da infância na América latina, em países cujas políticas para a infância assumem compromisso com a convenção, se encontram fortemente afetados por efeitos de processos coloniais que colocam as crianças em situação de pobreza infantil.

Os estudos sobre a pobreza infantil apresentam duas linhas principais de análise: unidimensional e multidimensional (BASTOS, 2016). O entendimento e dimensionamento da pobreza infantil, na perspectiva unidimensional, toma as privações advindas de fatores econômicos, representados na falta ou baixa renda familiar que incidem, sobretudo, na garantia dos direitos de provisão. A perspectiva multidimensional, por sua vez, assume que a pobreza infantil se configura na intersecção de diversos fatores, além dos aspectos econômicos se perfilam aspectos sociais, políticos, culturais, construídos e situados histórica e geograficamente. Assim, na perspectiva multidimensional da pobreza infantil que consideramos nesse texto, o conjunto de privações incide tanto na violação de direitos de provisão, como na violação de direitos de proteção e, também, na violação de direitos de participação.

No contexto sócio-histórico latino-americano as crianças sofrem efeitos dos processos coloniais que afetam as narrativas culturais, interseccionando pobreza, gênero e infância, que persistem, inviabilizando a garantia dos direitos previstos na CDC.

A partir dessa contextualização, apresentamos nosso foco de interesse no questionamento sobre o limiar existente entre a violação e a garantia dos direitos da infância em situação de pobreza infantil que intersecciona diversos tipos de violências, com raízes no colonialismo. Colocamos a ênfase da discussão na infância institucionalizada com o propósito 
de garantir seus direitos de proteção. Essa constatação pode ser elucidada na análise das falas sobre direitos humanos, coletadas em pesquisa de campo, realizada em uma instituição que acolhe meninas e adolescentes na Guatemala, em diálogo com os referenciais sobre processos coloniais e decolonialidade (LUGONES, 2014; QUIJANO, 2005; SEGATO, 2012).

\section{A escuta das vozes de adolescentes institucionalizadas na pesquisa em campo}

Os dados empíricos do presente trabalho são oriundos de uma pesquisa internacional que investigou o contexto de garantia e violação dos direitos de crianças e adolescentes em quatro países da América Latina. Nesse texto, trazemos os dados relativos a um programa social localizado na cidade da Guatemala que atende meninas e adolescentes vítimas de violências produzidas em contextos fortemente atingidos pela pobreza infantil na perspectiva multidimensional.

A escuta dos sujeitos se orientou em roteiro de entrevista semiestruturado, contendo questões abertas e fechadas, com o intuito de identificar "ideias, crenças, maneiras de pensar [...]; condutas; projeções para o futuro; razões conscientes ou inconscientes de determinadas atitudes e comportamentos"' (MINAYO, 2013, p. 262).

A coleta de dados foi realizada mediante entrevistas individuais, com 24 adolescentes com idade entre 12 e 18 anos, 13 pais e/ou responsáveis e 22 profissionais que atuam na instituição. Os(as) participantes foram informados(as) acerca do estudo, bem como dos cuidados éticos da pesquisa, e concordaram em participar assinando o termo de consentimento ou assentimento.

Naquele contexto, todas as vinte e quatro participantes estavam institucionalizadas em virtude de violências multifatoriais sobre elas perpetradas, abrangendo: agressões físicas, psicológicas e sexuais. Portanto, a institucionalização ocorre em virtude de denúncias de violências contra as meninas e adolescentes, na maioria tipificadas como abusos, exploração e tráfico sexual, tendo o propósito protetivo durante o processo de investigação e julgamento do agressor.

Grande parte dessas violências são produzidas e justificadas em práticas intergeracionais e culturais largamente difundidas de opressão dos mais vulneráveis, em especial, crianças do sexo feminino, passando a ser reproduzidas e naturalizadas nos cotidianos infantis. A violência, conforme Chauí (1992, p. 22), abrange “[...] todo ato de força contra a espontaneidade, a vontade, a liberdade de alguém (coagir, constranger, torturar, brutalizar); todo ato de transgressão contra alguém ou contra o que uma sociedade define como justo e 
como direito [...]". Assim, as violências podem se manifestar de diversas formas, como: "[...] ato de brutalidade, sevícia, abuso físico e psíquico contra alguém e caracteriza relações intersubjetivas e sociais definidas pela opressão e pela intimidação" (CHAUÍ, 1992, p. 22).

A investigação se referenda nos pressupostos da pesquisa qualitativa, reunindo elementos do círculo hermenêutico-dialético que consiste em um "processo de construção e de interpretação hermenêutica de um determinado grupo [...] um vai-e-vem constante entre as interpretações e reinterpretações sucessivas (dialética) dos indivíduos" (ALLARD, 1996, p. 5051). Os dados gerados foram sistematizados, tendo a orientação da análise de conteúdo, abrangendo: “1) A pré-análise; 2) a exploração do material; 3) o tratamento dos resultados, a inferência e a interpretação" (BARDIN, 2015, p. 95).

Em um permanente diálogo entre o(a) pesquisador(a) e os(as) interlocutores(as), a pesquisa qualitativa se efetiva em uma constante construção, não há hierarquias nesse processo interseccional, fato que possibilita um constante repensar sobre a "fala em seu contexto para entendê-la a partir do seu interior e no campo da especificidade histórica e totalizante, em que é produzida" (MINAYO, 2013, p. 231). Assim, o círculo hermenêutico-dialético provoca o movimento interseccional, colocando em diálogo os elementos do: a) Contexto histórico do colonialismo; b) Fala das meninas e adolescentes; c) Análise dos dados gerados; d) movimento hermenêutico dialético de interpretação, entendimento e crítica.

\section{Direitos mais importantes na perspectiva das falas das adolescentes}

Os direitos humanos têm sua história construída em um continuum de "lutas que o homem trava por sua própria emancipação e das transformações das condições de vida que essas lutas produzem” (BOBBIO, 2004, p. 51). Essas lutas visam a diminuição da precariedade das vidas e propõem condições de reconhecimento e proteção contra as inúmeras violações (BUTLER, 2018). Emergem, assim, no cenário político - mesmo com todas as ressalvas à visão opressora aí implícita, na instituição de um sujeito ocidental, homogêneo e universal declarações, convenções, tratados, estatutos e leis que estabelecem princípios básicos para a garantia e proteção da dignidade humana, dignidade essa, inerente a todo e qualquer indivíduo.

Todavia, apesar da redação da Declaração Universal dos Direitos Humanos ter completado mais de 70 anos, e a convenção dos Direitos da Criança já ter completado 30 anos, ainda nos deparamos com situações de privações e violações de direitos legais e até mesmo desconhecimentos estruturais da existência desses direitos. 
As falas de nossas interlocutoras, diante da pergunta aberta "o que você entende por direitos humanos?", demonstram uma heterogeneidade de entendimentos acerca do dimensionamento que os direitos humanos assumem na vida das adolescentes entrevistadas. As interlocutoras apontaram mais que uma visão, assim as respostas geradas transcendem o número de participantes. Os entendimentos apresentados no quadro 1 foram sistematizados por categorias, conforme os grupos de direitos de: provisão, proteção e participação.

Quadro 1 - Entendimento acerca dos Direitos Humanos

\begin{tabular}{|c|l|c|c|}
\hline Categorias & \multicolumn{1}{|c|}{ Tipificação de direitos } & Freq. & $\%$ \\
\hline Provisão & Educação, estudar, aprender, escola, ter família & 10 & $25 \%$ \\
\cline { 2 - 4 } & $\begin{array}{l}\text { Direitos básicos: moradia, alimentação, saúde, vestuário, } \\
\text { brincar }\end{array}$ & 11 & $27,5 \%$ \\
\hline Participação & Liberdade, ser livre, ser escutado & 4 & $10 \%$ \\
\cline { 2 - 4 } & Nome, identidade & 8 & $20 \%$ \\
\hline Proteção & $\begin{array}{l}\text { Proteção contra violências e/ou discriminações, respeito, } \\
\text { paz }\end{array}$ & 7 & $17,5 \%$ \\
\hline Total & & 40 & $100 \%$ \\
\hline
\end{tabular}

Fonte: elaborado pelos autores com dados da pesquisa empírica (2019).

A alta frequência dos direitos básicos representados nas falas das adolescentes, sobre o que entendem como direitos humanos, revelam a precariedade que a infância vem enfrentando, de modo especial a infância na América Latina, que vivencia continuamente relações hierárquicas de saber/poder e governamentalidade que classificam "vidas que são dignas de serem vividas e vidas que devem ser destruídas" (BUTLER, 2018, p. 42).

Encaminhadas por instâncias judiciais e inseridas em um contexto de pobreza e/ou extrema pobreza infantil, nossas interlocutoras constantemente vivenciam as limitações e constrangimentos da negação dos direitos básicos para a garantia de uma vida digna, como acesso à: educação, saúde, alimentação adequada, moradia, lazer, cultura e demais direitos que são indispensáveis para o desenvolvimento integral do ser humano.

A negação de direitos básicos fica evidente no desconhecimento da renda familiar mensal. $66,7 \%$ indicaram desconhecer os ganhos mensais de sua família, fator que revela a precariedade econômica vivenciada. E mesmo entre as interlocutoras que conhecem, 12,5\% responderam que a renda é inferior a 1 salário mínimo, que corresponde a cerca de 2.643,21 quetzales ou 1.287,98 reais em 2017.

Moradia precárias com famílias numerosas instaladas em 1 ou 2 cômodos abrem portas para inúmeras violências físicas, psicológicas e sexuais, e quando não é na própria casa que ocorrem é na busca de subempregos que acontecem. Dados do ministério da saúde pública e 
assistência social da Guatemala revelam que dos 6.161 casos de violências sexuais contra crianças e adolescentes registradas pelo sistema de saúde, $95 \%$ pertenciam ao sexo feminino, com predominância de identificações com etnias indígenas (SIGSA, 2015).

Tais números expõem a violência de gênero e raça que acometem a infância guatemalteca em seus cotidianos. Violência também sofrida por nossas interlocutoras, as quais se "manifestam tanto sob as formas de destruição corporal sem precedentes, como sob as formas de tráfico e comercialização de tudo o que estes corpos podem oferecer, até ao seu limite" (SEGATO, 2012, p. 108).

Essa colonialidade de corpos e vidas intersecciona em múltiplas violências que abarca os aspectos de classe, raça e gênero, promovendo "uma redução ativa das pessoas, a desumanização que as torna aptas para a classificação, o processo de sujeitificação e a investida de tornar o/a colonizado/a menos que seres humanos" (LUGONES, 2014, p. 939). Essa interseccionalidade ${ }^{3}$ de violências revela que não há opressões hierarquizadas, e nos permite visualizar as matrizes coloniais de raça, classe e gênero que subalterniza os indivíduos e suas identidades.

A própria institucionalização que visa a proteção de nossas interlocutoras revela-se como outro mecanismo de governamento, que sob a tutela do Estado, interrompem essas infâncias que tem seus direitos básicos violados, fato esse exposto pela representação social dos direitos humanos que elas expressam em suas falas. Essa "cultura ou banalização da violência" (ARENDT, 2000) encontra nas estruturas cisheteropatriarcais ${ }^{4}$ um terreno fértil para a normatização de comportamentos, fazendo com que os sujeitos inseridos nessa tutela estatal estejam expostos à violência do Estado-Nação que regula e "[...] ao mesmo tempo expulsa, negando e reduzindo ao silêncio" (FOUCAULT, 1985, p. 10) os sujeitos governamentados.

A vulnerabilidade das interlocutoras, constituída em contextos caracterizados pela pobreza infantil multidimensional, pode ser ampliada quando são forçadas a fugirem dos abusos

\footnotetext{
${ }^{3} \mathrm{~A}$ interseccionalidade como termo analítico sociológico foi inaugurado pela jurista norte-americana Kimberlé W. Crenshaw, que em seus escritos quis evidenciar os diversos e complexos aspectos identitários, principalmente os aspectos da raça e do gênero que subalternizava mulheres negras e reproduzia estruturas de violências e dominação. Emerge assim, principalmente como uma crítica à instituição de um feminismo branco, ocidental e universal. (Cf. CRENSHAW, Kimberlé Williams. "Demarginalizing the intersection of race and sex; a black feminist critique of discrimination doctrine, feminist theory and antiracist politics". University of Chicago Legal Forum, 1989, p. 139167).

${ }^{4}$ Estruturas cisheteropatriarcais referem-se às práticas que assentam seus valores nas normas de cisgeneridade, heterossexualidade e no patriarcado, ou seja, nessas estruturas os únicos sujeitos considerados pela norma hegemônica é o sujeito masculino, heterossexual e que se identifica com estruturas binárias de sexo/gênero e/ou gênero/genitália. Essas estruturas tendem a normatizar comportamentos, e os indivíduos que não se enquadram nessas molduras tendem a ser excluídos, estigmatizados e, por fim, eliminados. (Cf. HIRATA, Helena et al. (Org.) Dicionário Crítico do Feminismo. São Paulo: Editora UNESP, 2009).
} 
e violências, e se veem institucionalizadas para sua proteção, e ao mesmo tempo privadas de direitos de liberdade, como fica evidente na escolha de direitos mais importantes na situação de vida em que estão. Nessa questão, foram apresentados às interlocutoras os direitos previstos na Convenção dos Direitos da Criança (ONU, 1989) e solicitado que indicassem quais direitos, em ordem de importância, eram mais fundamentais naquele momento das suas vidas. Todas as adolescentes participantes listaram vários direitos, por essa razão o número de respostas apresentadas no quadro 2, obtidas de 24, participantes alcançou o total de 188 indicações.

Quadro 1 - Direitos previstos na CDC mais importantes para sua vida nesse momento

\begin{tabular}{|c|l|c|c|}
\hline Categorias & \multicolumn{1}{|c|}{ Tipificação de Direitos } & Freq. & $\%$ \\
\hline \multirow{5}{*}{ Provisão } & Saúde & 22 & $11,7 \%$ \\
\cline { 2 - 4 } & Educação & 18 & $9,6 \%$ \\
\cline { 2 - 4 } & Adoção (ter uma família) & 14 & $7,4 \%$ \\
\cline { 2 - 4 } & Esporte e recreação & 7 & $3,7 \%$ \\
\cline { 2 - 4 } & Cultura & 10 & $5,3 \%$ \\
\cline { 2 - 4 } & Convivência com os pais/responsáveis legais & 9 & $4,8 \%$ \\
\hline \multirow{5}{*}{ Proteção } & Vida & 23 & $12,2 \%$ \\
\cline { 2 - 4 } & Proteção contra todas as formas de violência & 16 & $8,5 \%$ \\
\cline { 2 - 4 } & Proteção contra trabalho ilegal e exploração econômica & 10 & $5,3 \%$ \\
\hline \multirow{5}{*}{ Participação } & Liberdade de opinião e expressão & 13 & $6,9 \%$ \\
\cline { 2 - 4 } & Identidade & 8 & $4,3 \%$ \\
\cline { 2 - 4 } & Liberdade de associação e crença & 7 & $3,7 \%$ \\
\cline { 2 - 4 } & Nacionalidade & 6 & $3,2 \%$ \\
\cline { 2 - 4 } & Orientação em e para os direitos humanos & 10 & $5,3 \%$ \\
\cline { 2 - 4 } & Profissionalização & $6,2 \%$ \\
\cline { 2 - 4 } & Informação & $2,7 \%$ \\
\cline { 2 - 4 } & Reintegração social & $2,2 \%$ \\
\hline Total & & 188 & $100 \%$ \\
\hline
\end{tabular}

Fonte: Elaborado pelos autores com dados da pesquisa empírica (2019).

A grande ênfase nos direitos de provisão, apontados pelas adolescentes no quadro 1, indica a precarização das condições de vida, na qual direitos básicos ainda são negados à infância aqui investigada. Os direitos de proteção mencionados denunciam a grave ameaça à vida e segurança em que se encontram, com suas infâncias interrompidas pela gravidez na adolescência, ocasionada pelos abusos sexuais sofridos, pelo trabalho infantil e pela extrema pobreza que priva e limita a infância ao acesso aos demais direitos presentes na CDC. Os direitos à participação também figuram nas falas como a necessidade do reconhecimento da infância como portadora de fala, escuta e vez.

Identidade, nacionalidade e liberdade (de opinião e expressão, de associação e crença) também revelam-se nas falas das crianças e adolescentes, "principalmente [como] um esforço para afirmar a sua liberdade e para dar à sua própria vida uma certa forma na qual é possível se reconhecer, [e] ser reconhecido pelos outros (FOUCAULT, 2010, p. 290)”.

Orientação em e para os direitos humanos, que prevê a compreensão, conscientização, conhecimento e vivência dos direitos humanos no cotidiano de suas vidas, também se revela 
um importante direito para as interlocutoras. Direito esse que pode se efetivar em suas vivências quando a educação promover práticas interculturais, que incluam todos os participantes internos e externos que integram o espaço educativo, conscientizando e contribuindo para a criação de uma cultura de direitos humanos e superação de práticas coloniais.

Interessante o fato de a educação representar o terceiro direito mais importante, ainda mais quando comparamos com a alta porcentagem (71\%) de repetência e abandono escolar experienciados pelas interlocutoras. E quando questionadas acerca dos motivos para retenção e abandono escolar, uma constelação de respostas foi apresentada, conforme indicado no quadro 3.

Quadro 3 - Razões para o abandono e retenção escolar

\section{Categorias}

(4) falta de recursos, (3) expulsa por não se portar bem, (3) não gostava de estudar, (2) institucionalização, (2) fugiu de casa por maltrato, (1) problemas em casa, (1) gravidez, (1) a mãe a tirou porque não queria que estudasse, (1) fugiu da instituição, (1) rebeldia por conta das amizades, (1) mudança de país, (1) foi retirada, (1) foi morar com a tia, (1) para ajudar a mãe que teve bebê.

Fonte: Elaborado pelos autores com dados da pesquisa empírica (2019).

Os motivos para abandono e retenção escolar ilustram a situação de pobreza infantil multidimensional a qual nossas interlocutoras estão submetidas, observamos o interseccionamento de fatores econômicos aliados a fatores culturais, sociais e políticos, ainda muito contaminados por narrativas coloniais hegemônicas. Narrativas que se manifestam de forma intergeracional, ou seja, não apenas fazem parte do cotidiano das adolescentes entrevistadas, como também de seus pais e responsáveis. Dos 13 pais e/ou responsáveis entrevistados na pesquisa, apenas 2 haviam completado a educação básica e, 1/3 deles se declararam como não alfabetizados.

Os dados da escolarização dos pais e responsáveis indicam que a violação do direito à educação, além de perpetuar condições de desigualdades sociais, influencia nas dimensões multidimensionais de estruturas hegemônicas que incidem sobre a precarização da infância na América-Latina. A baixa escolaridade dos familiares tem impactos diretos em níveis econômico, social e culturais, contribuindo para constrangimentos e sentimentos de vergonha que afetam a autoestima, as oportunidades de ingresso no mercado de trabalho e demais situações que impedem o desenvolvimento integral dos indivíduos. Além disso, a pouca ou inexistente formação escolar pode contribuir para a perpetuação de práticas intergeracionais abusivas que afetam diretamente a vida das crianças e adolescentes entrevistadas.

Quanto ao conhecimento acerca da renda familiar, 12 pais e/ou responsáveis responderam conhecê-la, e apenas 1 desconhecia a renda. Dos que afirmaram conhecer, 58,3\% 
disseram que ela era menor que 1 salário mínimo, e os demais $(41,7 \%)$ que era de 1 salário mínimo mensal. O não conhecimento acerca da renda familiar exposta pela mãe 6 confirma o fato de que apesar de contribuírem significantemente com os rendimentos financeiros da família, tendo tríplice ou quadruplas jornadas de trabalho, as mulheres ainda são privadas das tomadas de decisões acerca dos ganhos de seu trabalho. Situação que se agrava principalmente em contextos de trabalho doméstico e agricultura, que tendem a ser trabalhos desconsiderados e com pouca valorização social.

A precariedade econômica dos pais, mães e/ou responsáveis incide diretamente na inserção de crianças e adolescentes em subempregos, fator esse que contribui para a privação de diversos direitos da infância e, como apresentado pelos dados de nossa pesquisa, colabora exponencialmente para as violências sexuais. Violências essas que desde a colonização expropriam-se de corpos subalternizados.

As instituições educacionais nessa perspectiva apresentam-se, em muitos momentos, como incapazes de adaptar-se a esses fatos do cotidiano de crianças, adolescentes e de seus familiares. De tal maneira que essa perspectiva hegemônica, enraizada nos processos coloniais, gera e perpetua currículos fechados, professores(as) não preparados(as) para o diálogo intercultural e escolas incapazes de adaptarem-se à realidade dos educandos.

As falas das adolescentes, e a falta ou baixa escolaridade dos pais e responsáveis, permite observar que o direito à educação continua constantemente lhes sendo negado e violado e que as escolas se apresentam como instituições exímias em classificar, manter e regular os sujeitos de acordo com a normatividade social imposta. Aliás, a escola entende muito bem da marginalização de corpos, condutas e criação de imagens que definem o bom aluno e a boa aluna, o bom professor e a boa professora, na verdade as instituições educacionais "desde seus inícios, [...] exerceram uma ação distintiva. Elas se incumbiram de separar os sujeitos" (LOURO, 2012, p. 61).

\section{Educação intercultural como possibilidade de processos decoloniais}

A emancipação dos processos coloniais ainda é um desafio para os países latinos, ainda mais quando consideramos a eficácia das políticas/mecanismos de normatização, que objetivam que os indivíduos colonizados se adaptem constantemente à cultura do colonizador. A superação dessas práticas requer mudanças estruturais.

Essas mudanças, com aportes via educação, devem promover práticas que denunciem e ressignifiquem esses mecanismos de subalternização, resultantes da colonialidade de 
saber/poder, que promovem na vida de crianças e adolescentes em situação de pobreza infantil, violações de seus direitos.

O conceito de colonialidade de saber/poder foi introduzido nos estudos acadêmicos como um conceito de análise e denúncia das estruturas coloniais que excluíam, marginalizavam e negavam as memórias e culturas dos povos colonizados. Nesse processo colonizador emergiram novas identidades históricas que foram "produzidas sobre a ideia de raça [e] foram associadas à natureza dos papéis e lugares na nova estrutura global de controle do trabalho" (QUIJANO, 2005, p. 118).

Em contrapartida dessa imposição identitária vivenciada pelos colonizados, um novo padrão geocultural foi normatizado. O sujeito homem, branco, europeu e heterossexual tornouse o único padrão aceitável para que um indivíduo contasse para a política e a sociedade como um sujeito de direitos. E nesse limiar fronteiriço, os indivíduos, identificáveis pela hegemonia dominante, são legitimados pelo sistema de direitos, enquanto aqueles que não se enquadram nesses padrões são expostos às margens e nas margens o próprio sistema se encarrega de eliminá-los, quando não fisicamente, é no simbólico que essa eliminação ocorre.

Países da América Latina e a Guatemala, objeto de estudo desse trabalho, herdaram essas estruturas que mesmo na contemporaneidade continuam a promover violências como: a expropriação cultural, as repressões físicas e simbólicas das subjetividades e a promoção de um padrão de "normalidade" impossível do colonizado alcançar, que determina "quem é humano e, por conseguinte, qualificado para direitos humanos - e quem não é” (BUTLER, 2018, p. 115).

Tal eficácia dessas estruturas na vida de nossas interlocutoras fica evidente no constrangimento acerca das questões de identificação étnico-racial. Quando questionadas acerca de sua identificação étnica apenas 4 interlocutoras afirmaram pertencer a grupos indígenas, número preocupante quando observamos os dados censitários que registram que $40 \%$ da população guatemalteca pertence a etnias indígenas (ENCOVI, 2014). A pouca identificação com os povos originários demonstra o sucesso das estruturas e de suas políticas de branqueamento racial, na qual os sujeitos, para serem aceitos pela norma, tentam se identificar com as características hegemônicas impostas.

Como possibilidade de transformação social dessa realidade, acreditamos que a educação intercultural pode contribuir para a promoção de processos decoloniais, nos quais os sujeitos são convidados a promoverem "o diálogo e o intercâmbio de conhecimentos, saberes e práticas culturais" e, as instituições educacionais nessa perspectiva, “tornam-se um lugar plural 
e dialógico, onde os sujeitos são convidados a praticar a cidadania e respeitar a diversidade" (HANNA; RAMÃO; EYNG, 2013, p. 123-124).

Nessa perspectiva dialógica, a educação intercultural irá nortear-se no reconhecimento do outro, do diverso e do diferente, permitindo que culturas outras migrem das margens para o centro. Contribuindo para o desvelamento de hierarquias de opressão e poder que permeiam as relações sociais, principalmente as relações de classe, raça e gênero. Assim, a educação intercultural “[...] pressupõe superar o individualismo, os velhos discursos, as estruturas excludentes e as posturas discriminatórias em prol de um trabalho cooperativo, colaborativo, reflexivo e dialógico" (MUNSBERG; FERREIRA, 2018, p. 149). Somente desconstruindo e superando esses processos que promovem uma desumanização e uma subordinação de conhecimentos, colonizando corpos e vidas das crianças, é que os direitos humanos de fato irão serem garantidos.

Nessa direção, a "interculturalidade crítica possibilita a convivência de realidades plurais, o questionamento de discursos hegemônicos, padronizações e binarismos, bem como a desconstrução, problematização e relativização de estruturas e práticas sociais.” (MUNSBERG; FERREIRA, 2018, p. 149). Portanto, a interculturalidade se constitui ao mesmo tempo princípio e estratégia metodológica, em processos decoloniais, na garantia dos direitos da infância em contextos de extrema pobreza infantil.

\section{Considerações finais}

As diversas negações dos direitos humanos vivenciados pela infância demonstram a ineficácia do Estado na criação, implementação e avaliação de políticas públicas para a garantia de condições dignas para crianças e adolescentes.

As percepções acerca dos direitos evidenciaram um entendimento acerca dos direitos humanos que se restringe ao acesso de direitos básicos para a garantia de uma vida digna. Fato esse que demonstrou a eficácia das estruturas coloniais na classificação, marginalização e exclusão de sujeitos que interseccionam elementos identitários de classe, raça e gênero, tendo por consequência a ineficácia das políticas para a infância que prometem, mas não promovem seus direitos.

Os efeitos dos processos coloniais, discutidos e referendados nas percepções de meninas e adolescentes participantes da investigação empírica que subsidia esse estudo, evidenciam uma infância vítima de múltiplas violências. Essas violências podem se tornar mais agudas para as 
crianças institucionalizadas com o propósito de garantir seus direitos de proteção, mas que para isso tem privados os seus direitos de participação, em especial o direito de liberdade.

Nesse contexto, o limiar entre a garantia e a violação dos direitos da infância se torna muito tênue e frágil, a institucionalização legal, que visa a proteção contra diversas faces da violência, pode tornar-se mais um mecanismo normativo e regulatório de punição e controle, pautado em princípios e práticas advindos de processos coloniais, que culmina em infâncias interrompidas.

Esses princípios e práticas também perduram largamente nas instituições educacionais, que se apresentam como locais ambíguos que tanto podem reproduzir essas estruturas, como podem promover processos decoloniais de denúncia e superação das relações hierárquicas, quando apoiadas em princípios interculturais. Todavia, para que isso de fato ocorra é necessário a efetivação de políticas para a infância referendadas nos princípios decoloniais que viabilizem condições de vida digna para todas as crianças e adolescentes, mediante a materialização e a efetivação de políticas, programas e valorização dos profissionais que atuam na defesa e garantia de direitos de provisão, proteção e participação da infância.

AGRADECIMENTOS: O presente trabalho foi realizado com apoio da Coordenação de Aperfeiçoamento de Pessoal de Nível Superior - Brasil (CAPES) - Código de Financiamento 001, e do Conselho Nacional de Desenvolvimento Científico e Tecnológico (CNPq).

\section{REFERÊNCIAS}

ALLARD, Denis. De l'évaluation de programme au diagnostic socio- systéinique: trajet épistémologique. Université du Quèbec á Montréal. Montréal: Thèse de doctoraat em Sociologie, 1996.

ARENDT, Hannah. Eichman em Jerusalém. Um relato sobre a banalidade do mal. São Paulo: Companhia das letras, 2000.

BARDIN, Laurence. Análise de conteúdo. 5. ed. Portugal: Edições 70, 2015.

BASTOS, Amélia. A importância da perspectiva dos direitos da criança na análise do bemestar das crianças e jovens. In: BASTOS, A.; VEIGA, F. (org.). A análise o bem-estar das crianças e jovens e os direitos da criança. Famalicão: Edições Húmus, 2016. p. 27-34.

BOBBIO, Norberto. A era dos direitos. Rio de Janeiro: Elsevier, 2004.

BUTLER, Judith. Quadros de guerra: quando a vida é passível de luto? Rio de Janeiro: Civilização Brasileira, 2018. 
CHAUÍ, Marilena. Público, privado, despotismo. In: NOVAES, Adauto (Org.). Ética. São Paulo: Companhia das Letras, Secretaria Municipal de Cultura, 1992.

ENCOVI. Encuesta nacional de condiciones de vida. Instituto Nacional de Estadística, 2014. Disponível em:

https://www.ine.gob.gt/sistema/uploads/2014/02/26/L5pNHMXzxy5FFWmk9NHCrK9x7E5 Qqvvy.pdf. Acesso em: 09 jan. 2019.

FOUCAULT, Michel. História da sexualidade I: a vontade de saber. 6.ed. Rio de Janeiro: Graal, 1985.

FOUCAULT, Michel. Dits et écrits. Paris: Gallimard, v. 4, 1994.

FOUCAULT, Michel. Uma estética da existência. In: FOUCAULT, Michel. Ética, sexualidades, política. Rio de Janeiro: Forense Universitária, 2010.

HANNA, Paola Cristine Marchioro; RAMÃO, Valdacir José; EYNG, Ana Maria. Educação intercultural e garantia de direitos: limites e possibilidades para a superação das violências nas escolas. In: EYNG, Ana Maria (org.). Direitos Humanos e violências nas escolas: desafios e questões em diálogo. 1ed.Curitiba: CRV, 2013, v. 1, p. 123-146.

LOURO, Guacira Lopes. Gênero, sexualidade e educação: Uma perspectiva pósestruturalista. 14. ed. Petrópolis, RJ: Vozes, 2012.

LUGONES, Maria. Rumo a um feminismo decolonial. Revista de Estudos Feministas, v. 22, n. 3, p. 935-952, 2014.

MINAYO, Maria Cecília de Souza. O desafio do conhecimento. Pesquisa qualitativa em saúde. 4 ed. São Paulo: Hucitec-Abrasco, 2013.

NAÇÕES UNIDAS (ONU). A/RES/44/25: Convenção sobre os Direitos da Criança. Adotada e aberta para assinatura, ratificação e adesão da Assembleia Geral, em 20 de novembro de 1989, entrada em vigor em 2 de setembro de 1990. Disponível em: http://www.ohchr.org/en/professionalinterest/pages/crc.aspx. Acesso em: 14 jan. 2019.

MUNSBERG, João Alberto Steffen.; FERREIRA DA SILVA, Gilberto. Interculturalidade na perspectiva da descolonialidade: possibilidades via educação. Revista Ibero-Americana de Estudos em Educação, Araraquara, v. 13, n. 1, p. 140- 154, jan./mar., 2018. E-ISSN: 19825587. Disponível em:

https://periodicos.fclar.unesp.br/iberoamericana/article/view/9175/7151. Acesso em: 07 fev. 2019.

QUIJANO, Anibal. Colonialidade do poder, eurocentrismo e América Latina. In: LANDER, Edgardo (org). A colonialidade do saber: eurocentrismo e ciências sociais. Buenos Aires: Conselho Latino-americano de Ciências Sociais (CLACSO), 2005.

SEGATO, Rita Laura. Gênero e colonialidade: em busca de chaves de leitura e de um vocabulário estratégico descolonial. E-cadernos CES (Online), v. 18, p. 1-5, 2012. 
SIGSA [Sistema de información gerencial de salud]. Análisis de situación de casos de violência sexual. Guatemala, 2015. Disponível em:

http://epidemiologia.mspas.gob.gt/files/Publicaciones\%202016/Salas\%20Situacionales/Anális is $\% 20 \mathrm{de} \% 20$ situación $\% 20 \mathrm{de} \% 20$ casos $\% 20 \mathrm{de} \% 20$ Violencia\%20Sexual\%20año\%202015.pdf. Acesso em: 04 out. 2018.

SOARES, Natalia Fernandes. Direitos da criança: utopia ou realidade. In: PINTO, Manuel; SARMENTO, Manuel José Jacinto. (Org.). As Crianças: contextos e identidades. Braga: Centro de Estudos da Criança da Universidade do Minho. 1997, p.75-111.

\section{Como referenciar este artigo}

PACHECO, Eduardo Felipe Hennerich; EYNG, Ana Maria. A educação intercultural como possibilidade em processos decoloniais na garantia dos direitos da infância. Revista IberoAmericana de Estudos em Educação, Araraquara, v. 15, n. 1, p. 110-124, jan./mar. 2020. eISSN: 1982-5587. DOI: https://doi.org/10.21723/riaee.v15i1.12370

Submetido em: 20/03/2019

Revisões requeridas: $28 / 04 / 2019$

Aprovado em: 19/06/2019

Publicado em: 02/01/2020 